\title{
Bone Graft Wrapping with Cellulose Polymer Sheet in Posterior Spinal Fusion. A Technical Note
}

\author{
Gelalis D. loannis ${ }^{1}$, Karageorgos Athanasios ${ }^{2 *}$, Politis N. Aggelos ${ }^{1}$, Matzaroglou Charalambos ${ }^{3}$, Abuhemoud Q. Khaled ${ }^{1}$, Batzalexis A. \\ Nikolaos $^{1}$ and Beris E. Alexandros ${ }^{1}$
}

${ }^{1}$ Department of Orthopaedics, University Hospital of loannina, loannina, Greece

${ }^{2}$ Orthopaedic Department, Olympion Medical Center, Patras, Greece

${ }^{3}$ Department of Orthopaedics, University Hospital of Patras, Rion, Greece

\begin{abstract}
Background: Spinal fusion is one of most frequent employed procedures for treating various spinal morbidities. Pseudarthrosis remains a significant complication despite the use of hardware for mechanical stability. The type and proper placement of the bone graft have a fundamental role in achieving solid union. The ideal bone graft material should provide osteogenicity, osteoinductivity and osteoconductivity, an optimal biological reaction and no risk of transmission of diseases.

Methods: We describe a new technique of bone grafting in two patients who suffered from spinal stenosis. Local bone graft which obtained during decompression of the spine was mixed with bone marrow harvested from the posterior iliac crest. The mixture was wrapped in surgicel (Ethicon, Johnson \& Johnson Medical Ltd, Somerville, NJ, USA) and given a cylindrical shape. Finally, the handmade cylinders were placed laterally to the rod of the instrumentation, onto the decorticated transverse processes.

Results: The patients were followed radiographically every three months. The $x$-rays verified proper placement of the graft onto the transverse processes in both patients. Solid fusion was reported in both sides of the first patient at three months and at six months for the second. At one year postoperatively, fusion status was still graded solid.

Conclusion: The aforementioned technique uses the advantages of a bone auto graft which has been enhanced by bone marrow components, avoiding donor site morbidity. Using surgicel (Ethicon, Johnson \& Johnson Medical Ltd, Somerville, NJ, USA) we can adapt the graft to the desired size and shape and finally place it with accuracy onto the decorticated transverse processes. This is a promising technique concerning solid fusion and complications; however, it is a pilot study and needs more time and patients to obtain safe results.
\end{abstract}

Keywords: Bone autograft; Iliac crest bone graft; Local bone autograft; Postero-lateral spinal fusion

\section{Introduction}

Spinal fusion is one of most frequent employed procedures for treating various morbidities such as deformity, trauma and degenerative disc disease with instability.

The biological processes in bone regeneration in spinal fusion procedures require tree critical elements: an osteogenic potential that is capable of directly providing cells to the newly forming bone, osteoinductive factors that are able to cause the osteoblastic differentiation of osteoprogenitor stem cells, and osteoconductive scaffold that facilitates neovascularization and supports the in growth of bone. Furthermore, low-strain mechanical environment must be consistently maintained for the duration of the healing response. Union is achieved when this cellular osteogenic response incorporates and replaces grafted bone with a new matrix that is mechanically rigid in relation to the host bone. The ideal bone graft material possesses all of these three properties along with an optimal biological reaction and without a risk of transmission of diseases.

Iliac crest autograft has been used for many years to achieve lumbar fusion [1-4]. The most frequent complications following fusion surgery are pseudarthrosis and donor site morbidity. Despite the use of rigid instrumentation, the rate of pseudarthrosis remains significant with iliac crest autograft [4-7]. Furthermore donor site problems, including pain, paresthesias, hematoma and infection, have been reported in up to $50 \%$ of patients in some series [8-10].

The use of local autograft as an alternative in lumbar fusion surgery has been evaluated. It achieves a similar fusion rate in 1-level fusion with less morbidity compared to iliac crest. However, it seems that when multiple segments are fused, local bone grafting showed inferior results in fusion compared to iliac crest bone [11].

Major concern in posterolateral fusion still remains the carrier of the bone graft, which should have structural integrity, allowing it to resist compression from the surrounding paraspinal musculature and maintain a space where the posterolateral fusion can form [12-17].

Surgicel (Ethicon, Johnson \& Johnson Medical Ltd, Somerville, NJ, USA) is an oxidized cellulose polymer made fabric used for haemostasis in various surgeries, including spinal surgery. Recently, animal studies proposed a potential role of oxidized cellulose in new tissue regeneration [18]. Additionally, diced bone grafts wrapped in oxidized cellulose have proven useful in craniomaxillofacial region surgeries, as they combine the advantages of easier adaptation and molding [19].

We describe the details of a surgical technique where we used surgicel (Ethicon, Johnson \& Johnson Medical Ltd, Somerville, NJ,

*Corresponding author: Karageorgos Athanasios, Orthopaedic Department Olympion Medical Center, Patras, Greece, Tel: 0030 6972277818; Fax: 00302621 400400; E-mail: a.karageorgos@hotmail.com

Received November 23, 2011; Accepted December 13, 2011; Published December 16, 2011

Citation: loannis GD, Athanasios K, Aggelos PN, Charalambos M, Khaled AQ, et al. (2012) Bone Graft Wrapping with Cellulose Polymer Sheet in Posterior Spinal Fusion. A Technical Note. J Spine 1:102. doi:10.4172/2165-7939.1000102

Copyright: (C) 2012 loannis GD, et al. This is an open-access article distributed under the terms of the Creative Commons Attribution License, which permits unrestricted use, distribution, and reproduction in any medium, provided the original author and source are credited. 
USA) to wrap the diced local autograft, which had been previously mixed with bone marrow $(4 \mathrm{cc})$, and place it in the desired position over the transverse processes during instrumented posterolateral fusion of the lumbar spine. We report our primary results in two patients, a 67 and a 68 year old female and male respectively, with instrumented posterolateral fusion for degenerative lumbar spinal stenosis.

\section{Materials and Methods}

\section{Case 1}

A 67 year old female (S.M.) presented in our outpatient clinic complaining of severe pain to her lower back, continuous for approximately two months and claudication during a walking distance over 200 meters. She had a five year clinical history of lower back pain and she was diagnosed with disk degeneration and grade I spondylolisthesis of L4-L5. Within the last two months she visited the emergency department twice, and she was treated with a combination of anti-inflammatory and muscle relaxant drugs with no relief. She was advised to perform a magnetic resonance imaging (MRI) scan to her lumbar spine, and she was diagnosed with degenerative lumbar spinal stenosis and grade I spondylolisthesis of L4-L5 spine. An instrumented posterolateral fusion and decompression of the lumbar spine from L3 to L5 level was performed.

\section{Case 2}

A 68 year old male (M. B), had a previous history of 11 years lower back pain associated with intermittent sciatica pain and claudication. Lately, the patient suffered from increasing numbness in both legs and feet. At clinical examination he was found having impaired reflexes and associated weakness to both legs. A recent electromyogram showed impaired chronic function of L4 and L5 root. Radiographic and MRI scans confirmed the diagnosis of degenerative lumbar spinal stenosis and scoliosis with a left lumbar scoliotic curve of 20 degrees. Wide decompression from L2 to L5 level, instrumented posterolateral fusion from L1 to L5 and correction of the scoliotic curve was performed.

\section{Surgical technique}

The local autograft used for grafting was obtained during decompression of the spine. The cephalad and caudal spinous processes were totally ambulated and a wide decompression of the preoperatively marked levels was performed. The harvested pieces of the resected spinous processes, lamina, medial facet and part of the lateral facet as well as osteophytic projections were then cleaned of all soft tissues and bone bits were diced in to small pieces of maximum diameter of $5 \mathrm{~mm}$ with the usage of a small roger.

The autologous local bone graft pieces were mixed with bone marrow $(4 \mathrm{cc})$ harvested with a syringe from the posterior iliac crest and given a cylindrical shape sized $9 \times 2 \mathrm{~cm}$ (Figure 1). Then they were wrapped in Surgicel (Ethicon, Johnson \& Johnson Medical Ltd, Somerville, NJ, USA) original gauze, which was previously cut in dimensions of $10.16 \mathrm{X} 10.16 \mathrm{~cm}$ The two edges of the surgicel were tied with an absorbing synthetic suture Vicryl Rapide 3-0, FS-2 (Ethicon, Johnson \& Johnson Medical Ltd, Somerville, NJ, USA) (Figure 2). Finally, the two handmade cylinders were placed laterally to the rod of the instrumentation, onto the decorticated transverse processes.

\section{Results}

The assessment of fusion was conducted radiographically every 3 months for the first year. Fusion was evaluated by two independent spinal surgeons who where blinded to each other and blinded to the study. Fusion grade was defined as solid fusion, indefinite and nonunion based on evidence from plain radiographs.

Fusion was reported as solid in both sides of the first patient at three months postoperatively. Fusion in the second patient was considered as indefinite at three months (Figure 3A \& 3B). However, at six months postoperatively there was evidence of solid fusion in both patients. At one year after surgery, fusion status was still graded solid in both patients.

\section{Discussion}

Obtaining a solid arthrodesis is the main objective in lumbar surgical procedures. Successful fusion depends on a number of surgical and host factors including the selection of a bone graft or bone graft substitute with adequate osteoconductive and osteoinductive properties.

Spine surgeons use instrumentation to maintain low-strain mechanical environment for the duration of the healing response. Iliac crest bone graft remains the standard to which bone graft substitutes and bone graft enhancers are compared, combining osteogenic, osteoinductive and osteoconductive properties. Nevertheless, published fusion rates for posterolateral fusion using iliac crest bone graft vary

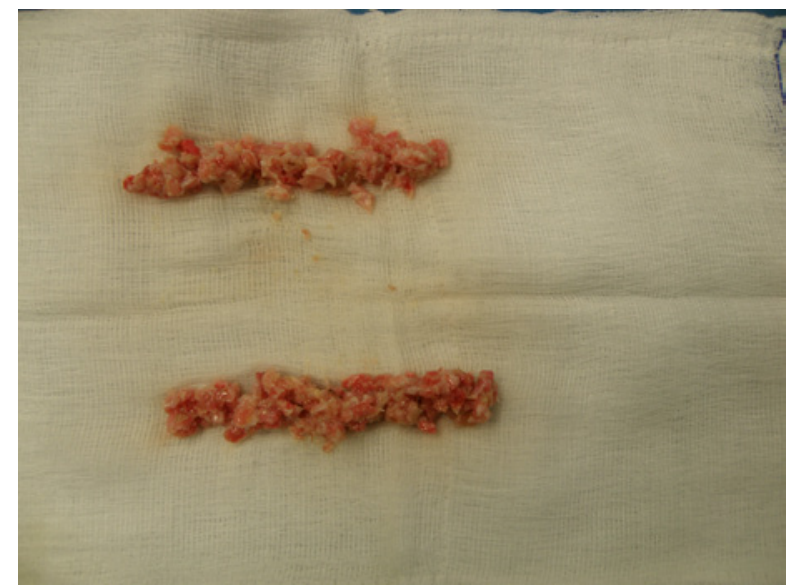

Figure 1: Autologous local bone graft pieces mixed with bone marrow. It has been given a cylindrical shape to fit accurately onto the transverse processes.

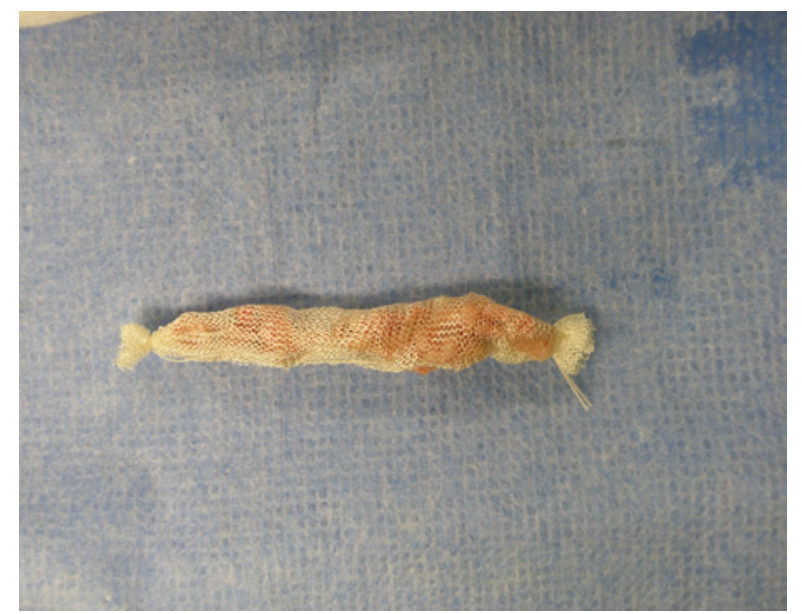

Figure 2: Autologous local bone graft pieces wrapped in Surgicel. Adaptation and molding of local bone graft is very easy. 

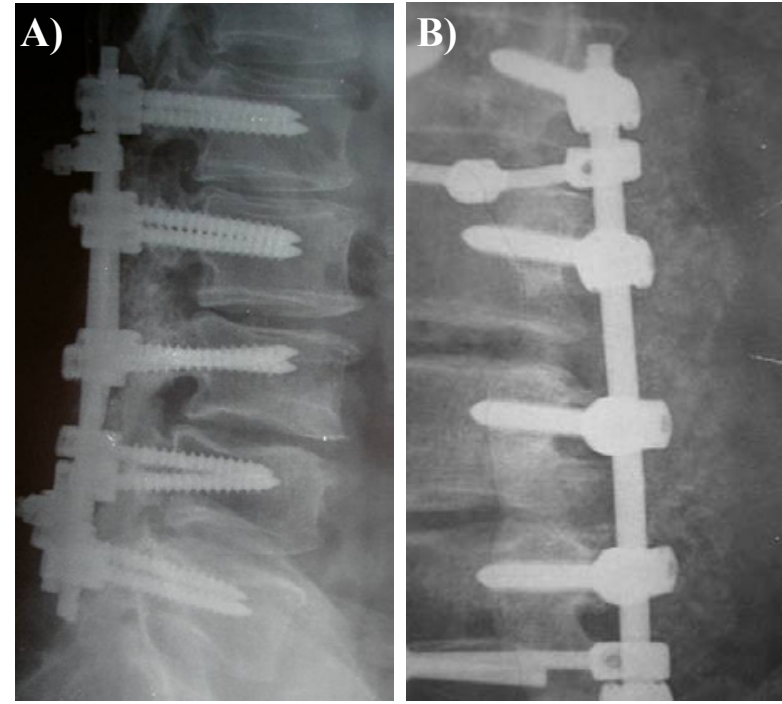

Figure 3: Radiographically appearance of the graft at three months. Although the fusion is considered indefinite the graft is located firmly at the desired position.

from $40 \%$ to $80 \%$ [20,21]. Furthermore, a number of complications associated with iliac crest bone graft harvest have been widely reported [9,22-27].

Due to these drawbacks a variety of bone grafts have been developed for use in posterolateral fusion in lumbar spine.

Allograft bone is a widely used grafting material, commonly regarded as a bone graft extender. Allografts have an osteoconductive scaffold with minimal osteoinductive factors; however, they are not able to provide osteogenic cells because of the processing that they undergo in order to decrease their antigenicity. Compared to autografts, the allografts are incorporated slower and less completely with decreased vascularization and osteoconduction [28]. Beyond the question of efficacy, the primary concern surrounding the use of allograft bone is the risk for disease transmission.

Demineralized bone matrix (DBM) is a class of bone graft materials made by processing allograft bone. Demineralization process leaves behind the small quantities of bone morphogenetic protein (BMP) found in allograft bone, and thus generates osteoinductive potential. However, DPMs lack structural strength and also there is concern about their osteogenic potential $[29,30]$.

Cell-based strategies describes a variety of techniques by which cells with osteogenic potential are collected, concentrated, and applied as bone graft enhancers [31-34]. The most common target cells are bone marrow components and platelets. Bone marrow components have promising results in spinal fusion as is a well established source of mesenchymal stem cells (MSCs). There are animal models [35] and clinical studies [36] that have demonstrated efficacy in spinal fusion using bone marrow-derived mesenchymal stem cells (MSCs). On the other hand there is data that questions the efficacy of platelets in posterolateral fusion [37-39]. A drawback in the use of cell-based strategies is that these materials totally lack structural strength and can only be used as bone graft enhancers.

BMPs are members of the transforming growth factor-beta superfamily. By binding to specific receptors present on the surface of the osteogenic progenitor, intracellular cascades - which resemble endochondral ossification - are activated. Although, they have the greatest osteogenic potential, they lack osteoconductivity, diffuse away from the fusion site easily, and become inactivated in vivo when they used alone. Therefore, recombinant BMPs are combined with a carrier matrix that serves to retain the concentration and releases them consistently over time. Drawbacks to their use are complications such as, osteolysis, swelling/edema, heterotopic bone formation, antibody reaction, and their high cost.

Ceramic scaffolds (calcium phosphates) and a variety of new agents as calcium sulfate, bioactive glass, dual hydroxyapatite composite with porous and solid parts, poly and highly porous hydroxyapatite, have been tested in animal studies and have demonstrated to possess an osteoconductive ability [37,40-45]. Nevertheless, they lack osteogenic and osteoinductive activity, thus becoming effective only as vehicles of other bone grafts.

Local autografts can be used as an alternative to iliac crest autograft. They combine osteogenic, osteoinductive and osteoconductive properties, avoiding morbidity associated with the harvesting of iliac crest bone autograft. Concerns may be raised about the sufficient quantity [11] and the placement of the local autograft in cases of posterolateral fusion. Cammisa et al. [46] suggested that autogenous bone graft volumes of $10 \mathrm{cc}$ or less, in one-level fusion, were of limited value.

In our proposed technique the local bone graft, coming from spinous processes, lamina, posterior and medial portions of facet, as well as osteophytic projections, was cleaned of all soft tissues and bone bits were diced in to small pieces. Local autograft was then mixed with bone marrow $(4 \mathrm{cc})$ harvested with a syringe from both posterior iliac crests. The autologous bone graft pieces were given a cylindrical shape and they were wrapped in surgicel (Ethicon, Johnson \& Johnson Medical Ltd, Somerville, NJ, USA) original gauze. The use of surgicel (Ethicon, Johnson \& Johnson Medical Ltd, Somerville, NJ, USA) aimed in taking advantage of the features of easy adaptation and molding [19], optimizing the connective tissue formation and giving support to the regenerating tissue [18].

The first results, using this technique, are promising as far as concern solid fusion and complications. However, this is a pilot study which presents a new technique of collection, preparation, and placement of local bone autograft mixed with bone marrow in posterolateral spine fusion, and needs more time and patients to obtain safe results.

\section{References}

1. Herkowitz HN, Kurz LT (1991) Degenerative lumbar spondylolisthesis with spinal stenosis. A prospective study comparing decompression with decompression and intertransverse process arthrodesis. J Bone Joint Surg Am 73: 802-808.

2. Zdeblick TA (1993) A prospective, randomized study of lumbar fusion Preliminary results. Spine 18: 983-991.

3. Thomsen K, Christensen FB, Eiskjaer SP, Hansen ES, Fruensgaard S, et al (1997) 1997 Volvo Award winner in clinical studies. The effect of pedicle screw instrumentation on functional outcome and fusion rates in posterolateral lumbar spinal fusion: a prospective, randomized clinical study. Spine (Phila Pa 1976) 22: $2813-2822$.

4. Fischgrund JS, Mackay M, Herkowitz HN, Brower R, Montgomery DM, et al. (1997) 1997 Volvo Award winner in clinical studies. Degenerative lumbar spondylolisthesis with spinal stenosis: a prospective, randomized study comparing decompressive laminectomy and arthrodesis with and without spinal instrumentation. Spine (Phila Pa 1976) 22: 2807-2812. 
Citation: Ioannis GD, Athanasios K, Aggelos PN, Charalambos M, Khaled AQ, et al. (2012) Bone Graft Wrapping with Cellulose Polymer Sheet in Posterior Spinal Fusion. A Technical Note. J Spine 1:102. doi:10.4172/2165-7939.1000102

Page 4 of 4

5. Glassman SD, Dimar JR 3rd, Burkus K, Hardacker JW, Pryor PW, et al. (2007) The efficacy of rhBMP-2 for posterolateral lumbar fusion in smokers. Spine (Phila Pa 1976) 32: 1693-1698.

6. Dimar JR, Glassman SD, Burkus KJ, Carreon LY (2006) Clinical outcomes and fusion success at 2 years of single-level instrumented posterolateral fusions with recombinant human bone morphogenetic protein-2/compression resistan matrix versus iliac crest bone graft. Spine (Phila Pa 1976) 31: 2534-2539.

7. Dimar JR 2nd, Glassman SD, Burkus JK, Pryor PW, Hardacker JW, et al (2009) Two-year fusion and clinical outcomes in 224 patients treated with a single-level instrumented posterolateral fusion with iliac crest bone graft. Spine J 9: $880-885$

8. Summers BN, Eisenstein SM (1989) Donor site pain from the ilium. A complication of lumbar spine fusion. J Bone Joint Surg Br 71: 677-680

9. Banwart JC, Asher MA, Hassanein RS (1995) lliac crest bone graft harvest donor site morbidity. A statistical evaluation. Spine (Phila Pa 1976) 20: 1055 1060

10. Silber JS, Anderson DG, Daffner SD, Brislin BT, Leland JM, et al. (2003) Donor site morbidity after anterior iliac crest bone harvest for single-level anterio cervical discectomy and fusion. Spine (Phila Pa 1976) 28: 134-139.

11. Sengupta DK, Truumees E, Patel CK, Kazmierczak C, Hughes B, et al (2006) Outcome of local bone versus autogenous iliac crest bone graft in the instrumented posterolateral fusion of the lumbar spine. Spine (Phila Pa 1976) 31: $985-991$

12. Boden SD, Kang J, Sandhu H, Heller JG (2002) Use of recombinant human bone morphogenetic protein-2 to achieve posterolateral lumbar spine fusion in humans: a prospective, randomized clinical pilot trial: 2002 Volvo Award in clinical studies. Spine (Phila Pa 1976) 27: 2662-2673

13. Glassman SD, Dimar JR, Carreon LY, Campbell MJ, Puno RM, et al. (2005) Initial fusion rates with recombinant human bone morphogenetic protein-2/ compression resistant matrix and a hydroxyapatite and tricalcium phosphate/ collagen carrier in posterolateral spinal fusion. Spine (Phila Pa 1976) 30: 16941698.

14. Boden SD, Martin GJ Jr, Morone M, Ugbo JL, Titus L, et al. (1999) The use of coralline hydroxyapatite with bone marrow, autogenous bone graft, or osteoinductive bone protein extract for posterolateral lumbar spine fusion. Spine (Phila Pa 1976) 24: 320-327.

15. Martin GJ Jr, Boden SD, Marone MA, Marone MA, Moskovitz PA (1999) Posterolateral intertransverse process spinal arthrodesis with rhBMP-2 in a nonhuman primate: important lessons learned regarding dose, carrier, and safety. J Spinal Disord 12: 179-186.

16. Minamide A, Kawakami M, Hashizume H, Sakata R, Tamaki T (2001) Evaluation of carriers of bone morphogenetic protein for spinal fusion. Spine (Phila Pa 1976) 26: 933-939.

17. Suh DY, Boden SD, Louis-Ugbo J, Mayr M, Murakami H, et al. (2002) Delivery of recombinant human bone morphogenetic protein-2 using a compressionresistant matrix in posterolateral spine fusion in the rabbit and in the nonhuman primate. Spine (Phila Pa 1976) 27: 353-360.

18. Sari A, Tuncer S, Ayhan S, Elmas C, Ozogul C, et al. (2006) What wrapped perichondrial and periosteal grafts offer as regenerators of new tissue. J Craniofac Surg 17: 1137-1143.

19. Isken T, Alagoz SM, Onyedi M, Izmirli H (2008) Use of diced bone grafts wrapped in surgicel in the augmentation of maxillofacial area. J Craniofac Surg 19: $1440-1445$.

20. Bono CM, Lee CK (2004) Critical analysis of trends in fusion for degenerative disc disease over the past 20 years: influence of technique on fusion rate and clinical outcome. Spine (Phila Pa 1976) 29: 455-463.

21. Dawson EG, Lotysch M 3rd, Urist MR (1981) Intertransverse process lumbar arthrodesis with autogenous bone graft. Clin Orthop Relat Res 154: 90-96.

22. Rihn JA, Gates C, Glassman SD, Phillips FM, Schwender JD, et al. (2008) The use of bone morphogenetic protein in lumbar spine surgery. J Bone Joint Surg Am 90: 2014-2025

23. Arrington ED, Smith WJ, Chambers HG, Bucknell AL, Davino NA (1996) Complications of iliac crest bone graft harvesting. Clin Orthop Relat Res 329 : 300-309.

24. Heary RF, Schlenk RP, Sacchieri TA, Barone D, Brotea C (2002) Persisten iliac crest donor site pain: independent outcome assessment. Neurosurgery 50: 510-516.
25. Sasso RC, LeHuec JC, Shaffrey C (2005) Iliac crest bone graft donor site pain after anterior lumbar interbody fusion: a prospective patient satisfaction outcome assessment. J Spinal Disord Tech 18: S77-S81.

26. Seiler JG 3rd, Johnson J (2000) lliac crest autogenous bone grafting: donor site complications. J South Orthop Assoc Summer 9: 91-97.

27. Singh K, Phillips FM, Kuo E, Campbell M (2007) A prospective, randomized double-blind study of the efficacy of postoperative continuous local anesthetic infusion at the iliac crest bone graft site after posterior spinal arthrodesis: a minimum of 4-year follow-up. Spine (Phila Pa 1976) 32: 2790-2796.

28. Tsuang YH, Yang RS, Chen PQ, Liu TK (1989) Experimental allograft in spinal fusion in dogs. Taiwan Yi Xue Hui Za Zhi. 88: 989-994.

29. Takikawa S, Bauer TW, Kambic H, Togawa D (2003) Comparative evaluation of the osteoinductivity of two formulations of human demineralized bone matrix. J Biomed Mater Res A 65: 37-42.

30. Traianedes K, Russell JL, Edwards JT, Stubbs HA, Shanahan IR, et al. (2004) Donor age and gender effects on osteoinductivity of demineralized bone matrix. J Biomed Mater Res B Appl Biomater 70: 21-29.

31. Bose B, Balzarini MA (2002) Bone graft gel: autologous growth factors used with autograft bone for lumbar spine fusions. Adv Ther 19: 170-175

32. Lowery GL, Kulkarni S, Pennisi AE (1999) Use of autologous growth factors in lumbar spinal fusion. Bone 25: 47S-50S

33. Slater M, Patava J, Kingham K, Mason RS (1995) Involvement of platelets in stimulating osteogenic activity. J Orthop Res 13: 655-663.

34. Siebrecht MA, De Rooij PP, Arm DM, Olsson ML, Aspenberg P (2002) Platelet concentrate increases bone ingrowth into porous hydroxyapatite. Orthopedics 25: $169-172$

35. Minamide A, Yoshida M, Kawakami M, Yamasaki S, Kojima H, et al. (2005) The use of cultured bone marrow cells in type I collagen gel and porous hydroxyapatite for posterolateral lumbar spine fusion.Spine (Phila Pa 1976) 30 1134-1138.

36. Gan Y, Dai K, Zhang P, Tang T, Zhu Z, et al. (2008) The clinical use of enriched bone marrow stem cells combined with porous beta-tricalcium phosphate in posterior spinal fusion. Biomaterials 29: 3973-3982.

37. Hadjipavlou AG, Simmons JW, Tzermiadianos MN, Katonis PG, Simmons DJ (2001) Plaster of Paris as bone substitute in spinal surgery. Eur Spine J 10 S189-S196.

38. Hee HT, Majd ME, Holt RT, Myers L (2003) Do autologous growth factors enhance transforaminal lumbar interbody fusion? Eur Spine J 12: 400-407.

39. Heise U, Osborn JF, Duwe F (1990) Hydroxyapatite ceramic as a bone substitute. Int Orthop 14:329-338.

40. Baramki HG, Steffen T, Lander P, Chang M, Marchesi D (2000) The efficacy of interconnected porous hydroxyapatite in achieving posterolateral lumbar fusion in sheep. Spine (Phila Pa 1976) 25: 1053-1060.

41. Flatley TJ, Lynch KL, Benson M (1983) Tissue response to implants of calcium phosphate ceramic in the rabbit spine. Clin Orthop Relat Res 179: 246-252.

42. Hile DD, Kandziora F, Lewandrowski KU, Doherty SA, Kowaleski MP, et al (2006) A poly(propylene glycol-co-fumaric acid) based bone graft extender for lumbar spinal fusion: in vivo assessment in a rabbit model. Eur Spine $\mathrm{J} 15$ 936-943.

43. Kaito T, Mukai Y, Nishikawa M, Ando W, Yoshikawa H, et al. (2006) Dua hydroxyapatite composite with porous and solid parts: experimental study using canine lumbar interbody fusion model. J Biomed Mater Res B App Biomater 78: 378-384.

44. Lindfors NC, Tallroth K, Aho AJ (2002) Bioactive glass as bone-graft substitute for posterior spinal fusion in rabbit. J Biomed Mater Res 63: 237-244.

45. Motomiya M, Ito M, Takahata M, Kadoya K, Irie K, et al. (2007) Effect of Hydroxyapatite porous characteristics on healing outcomes in rabbit posterolateral spinal fusion model. Eur Spine J 16: 2215-2224.

46. Cammisa FP Jr, Lowery G, Garfin SR, Geisler FH, Klara PM, et al. (2004 Two-year fusion rate equivalency between Grafton DBM gel and autograft in posterolateral spine fusion: a prospective controlled trial employing a side-byside comparison in the same patient. Spine (Phila Pa 1976) 29: 660-666. 